\title{
El tratamiento lexicográfico de las partículas discursivas: dificultades y propuestas
}

\author{
Carlos Meléndez Quero \\ Université de Lorraine \& CNRS, ATILF, UMR 7118, Nancy, F-54015, France
}

Titre: Difficultés et propositions pour le traitement lexicographique des particules discursives

Résumé : Dans cet article nous offrons quelques réflexions pour l'étude lexicographique des particules discursives. À partir de l'analyse de quelques adverbes évaluatifs émotifs de l'espagnol, nous essayons de souligner les difficultés dérivées de l'emploi de dictionnaires pour l'apprentissage du fonctionnement discursif de ces unités. Une fois les apports des dictionnaires de particules présentés, nous proposons une méthode de définition et d'explication lexicographique de ces mots en termes d'instructions discursives et de stratégies communicatives. Ce modèle permettra de résoudre les problèmes signalés et d’illustrer les ressemblances et différences entre expressions évaluatives analogues.

4 mots-clé : dictionnaires, lexicographie, apprentissage des langues, particules discursives.

Title: Difficulties and suggestions for the lexicographic treatment of discourse particles

\begin{abstract}
In the present paper we offer some reflexions for the discourse particles lexicographic study. Thanks to the analysis of some emotive evaluative Spanish adverbs, we try to emphasize the difficulties that the dictionaries usage generates for the learning of those unities discourse functions. After putting forward the particle dictionaries contributions, we suggest a method for the lexicographic definition and explanation of those words in terms of discursive instructions and communicative intentions. This model will enable us to resolve the previous problems and to illustrate the principal similarities and differences between some close evaluative expressions.
\end{abstract}

Key words: dictionaries, lexicography, language learning, discourse particles

\section{Introducción}

El tratamiento lexicográfico que puede recibir un signo está condicionado por las características y las restricciones inherentes a cada diccionario. Por lo tanto, la cantidad y el tipo de información recogida para una determinada unidad léxica pueden variar de un diccionario a otro en función de los objetivos inicialmente diseñados en la elaboración de 
cada repertorio lexicográfico ${ }^{1}$. Ahora bien, aunque la microestructura y la forma del artículo lexicográfico deben adaptarse, como es natural, a cada clase de diccionario, tales condicionantes no tienen que limitar o reducir la veracidad y la claridad expositiva de las informaciones presentadas, las cuales deberían resultar útiles para el lector².

La realización de una tesis doctoral en el ámbito de la lingüística discursiva ${ }^{3}$ y la participación en distintos proyectos de investigación ${ }^{4}$ sobre diccionarios de palabras modales nos ha permitido estudiar el tratamiento lexicográfico que reciben las partículas ${ }^{5}$ en los diccionarios. A partir de la revisión de las entradas lexicográficas de tres adverbios evaluativos de orientación desfavorable (desafortunadamente, infortunadamente y desgraciadamente), vamos a ilustrar algunos problemas observados en la práctica lexicográfica correspondiente a la descripción de estos signos discursivos y vamos a reflexionar sobre el tipo de descripción más adecuada para este tipo de elementos.

\section{Las limitaciones de los artículos lexicográficos en los diccionarios del español}

Como han analizado diferentes estudios metalexicográficos recientes (Martín Zorraquino 2003 y 2010b, Martínez Marín 2006, González Ruiz 2010, Meléndez Quero 2010 y 2014, Torner 2010 y 2013, etc.), la redacción de las entradas lexicográficas de las unidades de naturaleza discursiva (partículas, marcadores) en los diccionarios monolingües generales ha suscitado numerosos problemas. Así lo indican las palabras de Azpiazu Torres (1998-1999, 28), comentadas también en el trabajo de Perdiguero (2006): "es cierto que los diccionarios de español han descuidado tradicionalmente esta parte del léxico, en parte por pura imitación de la actitud académica, de modo que se han mostrado incapaces de dar cuenta de la evolución semántica y sintáctica que se ha operado en los adverbios en -mente con el

\footnotetext{
${ }^{1}$ Siguiendo a Porto Dapena (2002, 86 y ss.), el contenido de cada entrada lexicográfica ha de redactarse en consonancia con el tipo de diccionario que vaya a acoger a la palabra.

${ }^{2}$ Como indica Martín Zorraquino (2003, 441): "No es lo mismo, claro está, un diccionario general que un diccionario especializado (de partículas); conviene indicar, con todo, que en los dos casos debe tenerse en cuenta al posible usuario y ofrecer, por tanto, una información fácilmente comprensible y aplicable”.

3 La tesis está en línea en la Universidad de Zaragoza (Meléndez Quero 2009), y posteriormente publicada en dos volúmenes en papel (Meléndez Quero 2011a y 2011b).

${ }^{4}$ Nos referimos a los proyectos Diccionario de palabras modales del español actual (con glosario español/italiano) y Diccionario de palabras modales del español actual (E iniciación a la lexicografía bilingüe), financiados por el Departamento de Ciencia, Tecnología y Universidad del Gobierno de Aragón y al proyecto Diccionario de palabras modales del español actual, subvencionado por la Dirección General de Ciencia y Tecnología del Ministerio de Educación y Ciencia. Tales proyectos forman parte de la labor investigadora del Grupo H029 Pragmagrammatica peripheriae, dirigido por la Dra. Martín Zorraquino y financiado por el Gobierno de Aragón y el Fondo Social Europeo.

${ }^{5}$ Dentro de esta etiqueta pueden agruparse signos de diferente categoría (adverbios, locuciones, expresiones gramaticalizadas, etc.). Al igual que Martín Zorraquino (1992, 118119), usamos el término partícula "que alude simplemente a la estructura componencial de las unidades objeto de análisis y que tiene la ventaja de resultar apto para referirse a elementos que operan en la gramática de la oración y en la del discurso (o en el marco de la enunciación)”. Remitimos a Loureda Lamas y Acín Villas (2010, 20-21), González Ruiz y Llamas Saíz (2011, 9), Martín Zorraquino (2010a, 112) o Hummel (2012, 7-8), sobre las etiquetas (marcadores, signos discursivos) usadas para referirse a estos elementos.
} 
paso de los años”. Para ilustrar estas carencia, partiremos de las definiciones de los adverbios evaluativos acotados en algunos diccionarios de uso general de la lengua española: DUE (1966), VOX (1993), DEA (1999), LEMA (2001) y DRAE (2001) ${ }^{6}$.

\subsection{Problemas de lematización de los adverbios en -mente}

La primera gran dificultad hace referencia a la propia macroestructura de los diccionarios (cfr. Torner 2013, 471-483) y al problema de la inconsistencia en la lematización de los adverbios, que conlleva la ausencia de entrada lexicográfica de ciertos signos en algunos diccionarios del español. Así, aunque desgraciadamente aparece en todas obras citadas, sorprende que una unidad de uso frecuente en nuestros días como desafortunadamente no tenga entrada en DUE (1966), VOX (1993) o DRAE (2001). Este dato resulta todavía más llamativo si se tiene en cuenta que en estas últimas obras sí está infortunadamente, ausente en LEMA (2001) y apenas empleado por los hispanohablantes ${ }^{7}$.

Aunque la ausencia de desafortunadamente en los diccionarios citados puede estar motivada por tratarse de un adverbio sin sustantivo cognado -a diferencia de los adverbios desgraciadamente e infortunadamente, con sustantivos de la misma base léxica (desgracia e infortunio)-, la formación del adverbio por adición del sufijo -mente a partir del adjetivo femenino de la misma raíz (desafortunada) debería justificar la presencia de desafortunadamente en estos diccionarios del español, sobre todo si se considera que el adjetivo desafortunado sí aparece en tales obras ${ }^{8}$. A nuestro entender, todo diccionario actual de la lengua española debería integrar el adverbio evaluativo desafortunadamente, mucho más utilizado que el literario infortunadamente, y cuyo uso se está expandiendo cada vez más, especialmente en discursos formales de carácter periodístico, gracias a la analogía con el adverbio inglés unfortunately (cfr. Santos Río 2003, 55).

\subsection{Carencias de las entradas lexicográficas para los adverbios en -mente}

Otra cuestión discutida en estudios metalexicográficos (Azpiazu 1998-1999, 15-22 o Torner 2013, 484) ha sido el grado de afinamiento descriptivo de estos signos en los diccionarios monolingües. Evidentemente, las restricciones de espacio que limitan el

${ }^{6}$ Estos diccionarios aparecen en la bibliografía como Moliner (1966), Alvar Ezquerra (1993), Seco, Andrés y Ramos (1999), Battaner (2001) y Real Academia Española (2001).

${ }^{7}$ Así lo confirma la consulta del Corpus de Referencia del Español Actual (CREA) de la Real Academia Española, que permite recuperar únicamente 5 ejemplos de infortunadamente en el siglo veintiuno, frente a los 88 de desafortunadamente y los 291 de desgraciadamente. Por su parte, el Macrocorpus de la norma lingüística culta de las principales ciudades de España y de América Latina, editado por Samper Padilla, Hernández Cabrera y Troya Déniz (1997), no ofrece ningún registro de infortunadamente, frente a los 5 de desafortunadamente y los 29 de desgraciadamente. Además, Santos Río (2003, 93) califica a infortunadamente como "raro".

8 Así, en el diccionario académico, este adjetivo presenta una primera acepción como equivalente del sintagma sin fortuna y una segunda en la que es definido mediante los adjetivos desacertado e inoportuno (DRAE 2001, s.v. desafortunado). 
tamaño de las entradas lexicográficas en los diccionarios de uso general justifican el escaso tratamiento que se hace de las partículas discursivas. Ahora bien, más allá de la concisión con la que estos elementos puedan ser tratados, hemos encontrado algunas carencias que podrían ser solventadas.

Por un lado, una práctica lexicográfica muy habitual en la descripción de los adverbios terminados en -mente es definirlos retomando los sustantivos o adjetivos de la misma familia léxica. Así, desgraciadamente aparece definido en VOX (1993) mediante el sintagma con desgracia, en LEMA (2001) y DUE (1966) como equivalente de la locución por desgracia y, finalmente, en DEA (1999) a partir de la correspondencia con de manera desgraciada. Esta definición mediante sintagmas introducidos por la preposición de, seguidos del sustantivo manera y del adjetivo femenino singular es muy común en la delimitación de estos adverbios: por ejemplo, desafortunadamente equivale a de manera desafortunada en DEA (1999) y LEMA (2001), e infortunadamente a de manera infortunada en DEA (1999). Si bien, siguiendo a Torner (2007, 56-57) parece adecuado recurrir a las bases léxicas de los adverbios para descubrir los rasgos que influyen en su funcionamiento discursivo, el problema de las paráfrasis \{de modo/manera + adjetivo\} es que no permiten entrever todas las funciones adverbiales (cf. Perdiguero 2006) y que aluden al uso intraoracional de estos tres signos como adjuntos verbales, empleo poco habitual en español actual, donde la función más frecuente de desgraciadamente, desafortunadamente e infortunadamente es la de adverbios disjuntos que evalúan externamente el conjunto de la oración a la que hacen referencia9

Otro problema recurrente en la delimitación del significado de estos signos es el recurso a definiciones sinonímicas (cf. las críticas de Torner 2010, 103), que ofrecen el inconveniente de caer "fácilmente en la circularidad" (Martín Zorraquino 2003, 445). Por ejemplo, desgraciadamente se presenta en DRAE (2001) como sinónimo de lamentablemente y del sintagma de manera lamentable; e infortunadamente aparece en los diccionarios DRAE (2001) y VOX (1993) mediante la correspondencia con los sintagmas sin fortuna y con desgracia, este último ya utilizado en la definición de desgraciadamente.

A pesar de las estrechas relaciones que mantienen, de una parte, desgraciadamente y lamentablemente, y de otra parte, infortunadamente y desgraciadamente, al ser los tres adverbios de evaluación negativa, la descripción de estos signos en un diccionario no puede reducirse a un listado de equivalencias, pues requiere explicaciones adicionales $\mathrm{y}$, sobre todo, ejemplos auténticos que permitan ilustrar las acepciones presentadas y mostrar las condiciones de selección de tales signos. Ahora bien, el uso de sinónimos o de expresiones equivalentes, aunque no debe ser la base de la entrada lexicográfica, sí puede resultar útil para precisar determinadas acepciones y para explicitar las relaciones de cada palabra con otras unidades valorativas afines.

\footnotetext{
${ }^{9}$ Nos referimos a su función de disjuntos de actitud según Greenbaum (1969) o de satélites de actitud según Dik (1989). Para la distinción entre las funciones adverbiales de adjunto y disjunto y la determinación de los valores habituales de estos adverbios emotivos del español, remitimos a las monografías de Torner (2007) y Meléndez Quero (2011a y 2011b).
} 
Finalmente, entre las carencias en el tratamiento lexicográfico de los adverbios en los diccionarios monolingües se encuentra la ausencia de explicaciones funcionales sobre su uso en el discurso, aspecto indicado por Martínez Marín (2006, 1443), para quien los diccionarios del español "necesitan atender en el grado apropiado a los resultados que han aportado en las últimas décadas las corrientes lingüísticas de orientación pragmáticodiscursiva”. Aunque los pocos comentarios relacionados con el uso discursivo de estos signos pueden explicarse por las restricciones económicas de estos diccionarios generales, resulta más problemático que las pocas informaciones relativas a las circunstancias de uso de estas unidades en tales obras sean ambiguas y puedan aplicarse a varias expresiones evaluativas análogas. Veamos algunos ejemplos.

El diccionario LEMA (2001) aclara el significado de desafortunadamente diciendo que "suele utilizarse para hacer valoraciones o introducir informaciones negativas". Aunque este tipo de definición metalingüística (o impropia, según Torner 2010, 105) es cierta, podríamos preguntarnos cómo diferenciar desafortunadamente de otros adverbios evaluativos de orientación desfavorable como desgraciadamente o infortunadamente. Asimismo, las descripciones atingentes a desgraciadamente en DUE (1966) carecen de precisión al indicar que es "expresión muy frecuentemente antepuesta a la exposición de un suceso de malas consecuencias", sin señalar otras unidades como desafortunadamente que se caracterizan por dicho valor ${ }^{10}$. Por su parte, DEA (1999) afirma que desgraciadamente "generalmente precede a la mención de un hecho que se considera desgraciado o lamentable”, lo que deja entrever las relaciones de este signo con lamentablemente, pero que no determina ningún rasgo distintivo que distinga a ambos.

En definitiva, el tratamiento lexicográfico de estas unidades en los diccionarios generales de la lengua española revisados resulta bastante reducido y las definiciones en ellos recogidas apenas dejan entrever el funcionamiento discursivo de tales signos ni sus diferencias internas, lo que puede ocasionar problemas para los aprendientes que quieran profundizar en su estudio.

\section{Las entradas lexicográficas en los diccionarios de partículas discursivas}

Teniendo en cuenta que el diccionario "ha de ser una obra ligada necesariamente a los resultados de una investigación lingüística, esto es, del análisis de la lengua o lenguas particulares de que se trate” (Martínez Marín 2006, 1433-1434) y buscando profundizar en la explicación de estos elementos discursivos, diferentes equipos de investigación en el ámbito hispánico (cfr. la síntesis de Martín Zorraquino 2006, 51-52) se han centrado en los últimos años en la elaboración de diccionarios de partículas, cuyo interés no solamente

${ }^{10}$ Un análisis exhaustivo (cf. el capítulo VI de Meléndez Quero 2009) permite afirmar que dicha explicación define mejor a desafortunadamente, adverbio que destaca por su valor argumentativo y por presentar como información principal la referencia a esas consecuencias negativas implícitas o explícitas. Por su parte, por su mayor carga semántica, desgraciadamente parece poseer un valor más conclusivo y tiene como foco de información el discurso explícito sobre el que recae la evaluación negativa. 
abarca el ámbito de la gramática descriptiva, sino que alcanza otras perspectivas, como la lingüística contrastiva o la enseñanza y el aprendizaje del español como lengua materna y también como lengua extranjera por hablantes no nativos ${ }^{11}$.

Además del trabajo realizado en la Universidad de Zaragoza por el grupo Pragmagrammatica Peripheriae dirigido por la Dra. Martín Zorraquino, destaca la culminación de algunas obras, como el Diccionario de partículas de Santos Río (2003), el Diccionario de conectores y operadores del español de Fuentes Rodríguez (2009) o el Diccionario de partículas discursivas del español coordinado por Briz, Pons Bordería y Portolés (2008).

Para ilustrar el tratamiento lexicográfico que reciben las unidades discursivas en estas obras, vamos a revisar las delimitaciones de los signos que nos ocupan en los diccionarios de Santos Río (2003) y Fuentes Rodríguez (2009), dado que la obra coordinada por Briz, Pons y Portolés no recoge entradas para estos adverbios en -mente.

3.1. Diccionario de conectores y operadores del español de Fuentes Rodríguez (2009)

Aunque el diccionario de Fuentes Rodríguez (2009) no tiene entrada para desafortunadamente e infortunadamente ${ }^{12}$, su tratamiento de desgraciadamente permite advertir sus aportaciones para la descripción lexicográfica de estas expresiones.

Al presentar desgraciadamente como operador modal, Fuentes Rodríguez $(2009,105)$ se centra en la explicación del empleo extrapredicativo de este elemento evaluativo ${ }^{13}$. La autora presenta perfectamente las propiedades distribucionales de este adverbio en su función de disjunto extraoracional al destacar su independencia entonativa y su libertad posicional: "Aparece en inicio de un enunciado, intercalado o final. // Forma grupo entonativo independiente, aunque no aparezcan en lo escrito estas pausas” (Ibíd.). Asimismo, explica el posible alcance de la evaluación de este signo sobre "todo el enunciado" o "un sintagma o expresión, sobre el que se focaliza” y señala su posible uso autónomo como respuesta a una pregunta previa: "Puede apoyar también, en respuesta, a sí, no. O constituir él sólo la respuesta” (Ibíd.). Todas estas informaciones acompañadas de ejemplos documentados facilitan la comprensión del funcionamiento sintáctico de este adverbio en español actual.

Este diccionario añade también informaciones sobre el registro característico de desgraciadamente, que aparece como unidad no marcada al presentarse tanto en la lengua oral como escrita y en el registro coloquial y culto. Además, ofrece una variante a este

\footnotetext{
${ }^{11}$ Así, lo destaca Martín Zorraquino (1992, 122), para quien "las partículas constituyen, en fin, un aspecto problemático e importante en la didáctica de las lenguas. Sobre todo, en la enseñanza de una lengua extranjera (o segunda)”. Sobre este aspecto, véase también Meléndez Quero (2010, 138 y 2011c, 609-613).

${ }^{12}$ Estos dos adverbios tampoco aparecen en Fuentes Rodríguez y Alcaide Lara (1996).

${ }^{13}$ En el diccionario de Fuentes Rodríguez $(2009,105)$, el valor de desgraciadamente como adverbio de modo se menciona al recordar el origen de este signo, si bien en la explicación lexicográfica únicamente se presentan ejemplos que ilustran su empleo disjunto, dado que el objetivo de la entrada es describir su comportamiento como operador modal.
} 
adverbio en la expresión por desgracia, a la que se considera equivalente, aunque sin profundizar en las relaciones entre ambos signos.

Las informaciones recogidas en este diccionario amplían considerablemente las presentadas en los diccionarios generales y describen las posibilidades combinatorias del adverbio, al que se le considera acertadamente una "marca de modalidad expresivo-emotiva" (Ibíd.). Ahora bien, la definición de desgraciadamente ofrece deficiencias advertidas en los diccionarios de la lengua española. Por ejemplo, al señalar que este signo "expresa una emoción negativa ante lo dicho" y que con él "el hablante se lamenta de los hechos expuestos”, Fuentes Rodríguez $(2009,105)$ ofrece una descripción que podría ser también válida para lamentablemente, el cual, sin embargo, no es presentado como variante del adverbio que nos ocupa.

\subsection{Diccionario de partículas de Santos Río (2003)}

Por su parte, el diccionario de Santos Río (2003) ofrece una caracterización completa de desafortunadamente, infortunadamente y desgraciadamente, los cuales comparten, de acuerdo a la terminología de este autor, el funcionamiento como adverbios oracionales de evaluación factual cualitativa.

Muchas son las aportaciones que esta obra ofrece al conocimiento de los valores y empleos de estos adverbios. En primer lugar, Santos Río (2003, 55-56) distingue y explica con ejemplos pertinentes cada valor sintáctico que pueden desarrollar desafortunadamente y desgraciadamente en la actualidad, diferenciando su funcionamiento extrapredicativo como adverbios evaluativos y posteriormente sus empleos intraoracionales como adverbios de modo ${ }^{14}$. Esta delimitación categorial es fundamental en la descripción lexicográfica de estos adverbios, que pueden desarrollar las funciones de adjunto y disjunto, siendo este último el valor más repetido en la actualidad.

La descripción de Santos Río $(2003,56)$ del valor oracional de desgraciadamente ofrece, al igual que Fuentes Rodríguez $(2009,105)$, informaciones complementarias sobre su libertad posicional, su posible utilización en respuestas o su empleo como comentario evaluativo autónomo. A tales explicaciones, añade precisiones combinatorias del adverbio en las que advierte que no "precede a formas del subjuntivo" y que la valoración introducida puede ser “orientable mediante un complemento con para”, posibilidad esta última también descrita en la caracterización de desafortunadamente.

Sin embargo, en el diccionario de Santos Río se echa en falta una definición que permita dar cuenta del significado de estos adverbios y de sus condiciones de selección. La descripción de desafortunadamente en Santos Río $(2003,55)$ únicamente lo muestra como equivalente a desgraciadamente. Este tipo de definición circular no ayuda a comprender las instrucciones discursivas que configuran el significado de estos signos ni las diferencias

${ }^{14}$ Ahora bien, en el caso de infortunadamente, Santos Río (2003, 93) únicamente describe el valor extraoracional, presentándolo como adverbio raro y equivalente a por desgracia. 
entre ambos. De la misma manera, tanto la entrada de desgraciadamente como la de infortunadamente en el diccionario de Santos Río (2003, 56 y 93) coinciden en considerar a estos adverbios oracionales como equivalentes de por desgracia, sinonimia que debería ser completada con explicaciones adicionales que permitieran diferenciar estas expresiones.

En definitiva, el tratamiento de los adverbios acotados en estos diccionarios especializados aporta informaciones muy útiles sobre su comportamiento sintáctico, pero no profundiza en su definición. Desde nuestro punto de vista, la descripción de estos adverbios requiere definiciones de uso (Lara Ramos 2003, 113), funcionales (Porto Dapena 2002, 282-283) o impropias (Torner 2010, 105 y 203, 490), que expliquen sus circunstancias de uso y que, en la medida de lo posible, permitan distinguirlos de otras expresiones análogas, ya que, como indica Martín Zorraquino (1999, 70), “a dos signos diferentes les debe corresponder algún tipo de diversidad significativa o pragmática (incluso si se trata de significados no denotativos), pues no hay unidades superfluas en las lenguas”.

En el apartado que sigue ofrecemos una descripción lexicográfica completa de estos adverbios, intentado combinar las explicaciones de naturaleza sintáctica con informaciones sobre las instrucciones discursivas y pragmáticas que caracterizan su funcionamiento extraoracional ${ }^{15}$. En otras palabras, pretendemos no solamente dar cuenta de la caracterización categorial de estos adverbios, sino también de las relaciones discursivas que definen su significado y de las estrategias comunicativas y los efectos pragmáticos que, gracias a su significado, pueden desarrollar en el discurso. Este modelo de caracterización lexicográfica permitirá al usuario disponer de una herramienta de producción (cfr. Torner 2013, 483) en la que encontrará informaciones muy útiles para utilizar adecuadamente estas expresiones, aspecto que nos parece muy interesante desde el punto de vista del aprendizaje de una lengua.

\section{Modelo de tratamiento lexicográfico de las unidades objeto de estudio}

Desde nuestro punto de vista, un artículo lexicográfico que intente describir de forma precisa estos adverbios evaluativos debe tener una microestructura ${ }^{16}$ que permita, cuando menos, distinguir sus diferentes valores sintácticos para posteriormente ofrecer una definición y una explicación lexicográfica sobre sus usos.

\footnotetext{
${ }^{15}$ Seguimos el modelo de caracterización de Porroche Ballesteros (2005), donde se advierte la necesidad de describir estos tres componentes (gramatical, discursivo y pragmático) en la delimitación de los adverbios enunciativos.

${ }^{16}$ La delimitación de estos adverbios en un diccionario especializado puede ser introducida mediante anotaciones relativas a su grado de difusión y a sus ámbitos de uso. En el caso de los tres adverbios aquí considerados, se podría recordar que infortunadamente es apenas utilizado en español actual, a diferencia de desafortunadamente cuyo uso se está ampliando, aunque sin la frecuencia de desgraciadamente. Asimismo, el tratamiento lexicográfico de estos adverbios emotivos podría señalar que desgraciadamente es una unidad mucho más extendida en el español de España que desafortunadamente, cuyo uso parece más habitual en el español de América (cf. Meléndez Quero 2011a, cap. I).
} 


\subsection{Rasgos sintáctico-distribucionales}

En primer lugar, desafortunadamente, infortunadamente y desgraciadamente forman parte de los adverbios del español que "pueden presentarse en el esquema de los enunciados en dos posiciones estructurales: unas veces integrados en la estructura de la predicación matriz, otras ‘extramuros’ de tal estructura” (Fernández Fernández 1993, 191).

Aunque la doble posibilidad de funcionamiento extraoracional e intraoracional parece condición indispensable previa a la definición y explicación lexicográfica de las acepciones de estos adverbios, este tipo de distinciones categoriales se encuentra ausente en todos los repertorios que hemos consultado, con la excepción del Diccionario de partículas de Santos Río (2003).

Desde nuestro punto de vista, un artículo lexicográfico correspondiente a unidades como desafortunadamente, infortunadamente o desgraciadamente debe distinguir dos funciones o valores: su uso como adverbios disjuntos extraoracionales de evaluación emotiva negativa y su empleo como adverbios adjuntos integrados en la estructura predicativa de la oración. Para ilustrar la diferencia entre ambas funciones adverbiales, partimos de los siguientes ejemplos:

(1) El partido acabó, desafortunadamente.

(2) El partido acabó desafortunadamente.

En el primer caso, la coma que precede a desgraciadamente confirma su independencia entonativa y su carácter extrapredicativo en su función de disjunto de valoración emotiva; en este empleo, el adverbio evalúa de forma negativa el conjunto de la oración previa, como ilustra la paráfrasis atributiva correspondiente (es desafortunado que el partido acabara). En el segundo ejemplo, la posición posverbal y la ausencia de pausa entonacional de anticadencia, marcada con coma en la escritura, entre el verbo y el adverbio confirma el valor adjunto de desgraciadamente como adverbio de modo; en esta nueva función, el adverbio complementa al verbo que le precede y describe el modo o la manera en la que todo acabó, como confirma la enfatización ecuacional que se usa para parafrasear estas construcciones (fue \{de forma desafortunada / de modo desafortunado\} como el partido acabó).

La entrada lexicográfica de estos signos debe, por lo tanto, presentar epígrafes diferentes correspondientes a cada una de estas dos funciones adverbiales. Ahora bien, cabe preguntarse si el orden en que deben presentarse estos apartados en un diccionario puede realizarse por evolución genética a partir de los valores más cercanos a la etimología o según la frecuencia de aparición de cada una de estas funciones (cfr. Porto Dapena 2002, 224 y ss.). Siguiendo el modelo de Martín Zorraquino (2003, 447), nos decantamos por esta última opción y proponemos que aparezca en primer lugar la descripción del valor disjunto 
habitual de adverbios como desgraciadamente o desafortunadamente, dejando en último término la alusión a su empleo menos frecuente como adverbios adjuntos ${ }^{17}$.

Centrándonos en la función principal de estos adverbios como disjuntos, vamos a presentar un esbozo de tratamiento lexicográfico de dicho valor. A nuestro juicio, tras la etiqueta de adverbios disjuntos de valoración emotiva, se deberían señalar brevemente las propiedades distribucionales y entonativas de estos signos. Habría que recordar la libertad posicional de desafortunadamente, infortunadamente o desafortunadamente para aparecer delante, en medio o detrás del segmento discursivo al que hacen referencia, su independencia tonal debida a su carácter extrapredicativo e igualmente su posible funcionamiento autónomo, como respuesta o comentario evaluativo a un discurso previo. No nos detendremos en este punto, pues las descripciones realizadas en los diccionarios de Santos Río (2003, 56) y Fuentes Rodríguez (2009, 105) para desgraciadamente ilustran perfectamente estas propiedades distribucionales, que son compartidas por los tres adverbios objeto de estudio en su función de disjuntos.

\subsection{Definición y explicación lexicográfica}

Más interesante parece profundizar en la definición y explicación lexicográfica de estos adverbios y en sus diferencias, aspecto apenas abordado hasta el momento en los diccionarios del español.

Para ello, cabe preguntarse cuál es el tipo de descripción más apropiada para delimitar estas unidades discursivas. Siguiendo a Martín Zorraquino (2010a, 470) parece adecuado partir de una caracterización que combina "ciertos rasgos sémicos esenciales", junto a "rasgos instruccionales u operativos”. Sin olvidar el significado base y los rasgos semánticos que explican el uso discursivo de estos signos, conviene añadir explicaciones funcionales que permitan describir para qué pueden usarse estos adverbios valorativos y con qué intenciones comunicativas pueden ser empleados en la actualidad, delimitaciones que, desgraciadamente, no son habituales en la práctica lexicográfica.

\subsubsection{Descripción semántico-discursiva}

Siguiendo una concepción afín a la teoría de la argumentación y a la teoría de los estereotipos aplicadas por Donaire (2006), entendemos estos adverbios evaluativos como guías que conceden una orientación argumentativa a una serie de discursos implícitos o

\footnotetext{
${ }^{17}$ Nos basamos en datos extraídos de las documentaciones de estos adverbios en el CREA y en el Macrocorpus de la norma lingüística culta de las principales ciudades de España y de América. Para datos estadísticos sobre las funciones de ambas unidades, remitimos a Torner $(2007,123)$ o Meléndez Quero (2011b, 826).

En el caso de infortunadamente, la escasez de ejemplos del siglo XXI en CREA -cinco casos- impide hablar de un valor especialmente frecuente. Ahora bien, aceptando que es un adverbio en desuso, los escasos ejemplos documentados ilustran su función de disjunto, por lo que dicha acepción debería ser la primera en todo diccionario que incluya este signo.
} 
explícitos. A nuestro juicio, el significado inherente a estos adverbios nos dice cómo debemos entender o interpretar los discursos a los que hacen referencia.

Proponemos, por lo tanto, su descripción acompañada de instrucciones discursivas que permita dar cuenta del tipo de contextos o de enunciados en los que pueden ser empleados. Para ilustrar este tipo de caracterización, vamos a ofrecer un modelo de descripción lexicográfica de desgraciadamente, la cual nos llevará a mostrar sus afinidades y diferencias con los otros adverbios evaluativos de sentido negativo aquí acotados.

En primer lugar, la definición de desgraciadamente debe incluir alguna alusión al valor de fatalidad que conlleva. Así, el artículo lexicográfico atingente a esta unidad puede incluir una definición expresada en estos términos: "Desgraciadamente concede una orientación desfavorable a un discurso que es concebido como funesto, aciago o infausto y que, por su valor de tragedia o por su gravedad, puede dar motivo para la pena, la tristeza o el dolor”. Para ilustrar esta definición, aconsejamos partir de un ejemplo auténtico, documentado en un corpus de español actual, como el CREA:

(3) Desde Bahamontes hasta Induráin, el ciclismo español siempre ha tenido un importante protagonismo en el panorama internacional, pero nadie como El Chava para subir los más altos puertos de montaña sonriente y desafiante, con la misma alegría como la pena que ahora sentimos por un magnífico deportista que nos ha dejado, desgraciadamente, para siempre. (CREA: El País, 09/12/2003)

Este ejemplo proporciona un uso contextualizado del adverbio y confirma que la introducción de desgraciadamente acompaña un discurso que conlleva ese matiz de fatalidad: en este texto se hace alusión a la muerte de un ciclista cuya temprana desaparición provocó una gran conmoción en el mundo del deporte.

Esta carga emotiva y este grado de sufrimiento interno acercan el significado de desgraciadamente a otros adverbios evaluativos del español como lamentablemente o tristemente, pero lo alejan del adverbio formado a partir del adjetivo desafortunado. Por ello, es importante que la descripción de desgraciadamente advierta que, si bien la introducción de un adverbio como desafortunadamente puede también evaluar de forma negativa discursos relacionados con el fallecimiento de personas, no implica, en tales contextos, el rasgo de pesadumbre o de abatimiento de desgraciadamente. Para ilustrar esta diferencia fundamental en el significado de ambos adverbios, puede compararse el ejemplo anterior con el citado a continuación:

(4) Los trasplantes nacionales se practican desde hace más de treinta años, y sus resultados son comparables a aquellos de los mejores programas del mundo, a pesar de ser un campo en el que se sigue investigando. Desafortunadamente, la falta de una cultura de donación de órganos con este fin provoca que varios miles de mexicanos mueran en etapas productivas de su vida. (CREA: Investigación y Desarrollo. Suplemento de Ciencia y Tecnología de La Jornada, 08/2002)

En este caso, la elección de desafortunadamente incide en las consecuencias fatales de la ausencia de órganos para la población de México, pero no manifiesta un verdadero pesar o 
aflicción ante las muertes de los mexicanos, sentimiento que sí conllevaría el empleo de desgraciadamente.

Junto a este valor de tragedia, la relación semántica de desgraciadamente con el sustantivo de la misma familia léxica (desgracia) puede concederle, en ciertas ocasiones, un cierto matiz de 'fortuna adversa' o de 'mala suerte'. En este sentido, el adverbio puede ser definido también de la forma siguiente: "Desgraciadamente instruye una orientación negativa con respecto a un discurso adverso, que es presentado como fortuito o imprevisto, fruto de la mala suerte”. Para ejemplificar esta definición, véase el siguiente fragmento, donde se describe la repentina muerte de un chimpancé que, además de ser trágica en sí misma, resulta especialmente fastidiosa al producirse en un momento poco oportuno (cuando la joven Dona estaba a punto de alcanzar la edad adecuada para aparearse):

(5) Durante algunos años Dona y Spencer convivieron juntos en el zoo de Madrid, aunque nunca llegaron a tener crías. Desgraciadamente, cuando la joven Dona estaba a punto de alcanzar la edad adecuada para aparearse, Spencer enfermó y murió a los pocos días. Una vez más nos encontrábamos con un animal solitario (CREA: Manuel López, Un gorila con paperas. Historias de un veterinario entre monos, 2001)

En la delimitación de desgraciadamente parece oportuno destacar que este rasgo de 'fortuna adversa' puede asemejarlo a infortunadamente, adverbio que como apuntan algunas equivalencias -sin fortuna, con desgracia- ofrecidas en DRAE (2001) o VOX (1993), puede añadir a la negación de la suerte, la presencia de la mala suerte. Este aspecto puede ilustrarse con el siguiente texto donde infortunadamente evalúa negativamente una serie de discursos que presentan una sucesión inesperada de circunstancias adversas:

(6) “iQué piedra tan extraña!”, pensó tras un vaivén del mulo que le obligó a bajar la vista unos segundos. Era oval, extrañamente oval. La cogió con sus manos, la examinó e, infortunadamente, la piedra cayó al suelo, se golpeó con otra y se abrió por la mitad dejando al descubierto su contenido. (CREA: Bruno Cardeñosa, El código secreto. Los misterios de la evolución humana, 2001)

Aunque el significado de infortunadamente puede compartir ese rasgo de 'mala suerte' con desgraciadamente, no conlleva normalmente el valor de fatalidad y el grado de aflicción del anterior. Para completar la diferenciación semántica entre estos adverbios afines, puede explicarse que desafortunadamente únicamente señala la ausencia de 'fortuna', pero sin convocar necesariamente la mala suerte, que sí es inherente a los sustantivos desgracia (su primera definición en DRAE 2001 es "suerte adversa") e infortunio (definido como "suerte desdichada o fortuna adversa” en DRAE 2001).

\subsubsection{Funciones pragmáticas a partir del significado de estos signos}

A nuestro juicio, la presentación de estos adverbios en un diccionario debe responder a una doble pregunta: ¿qué significan y para qué se utilizan? Así, para completar las definiciones 
de desgraciadamente puede añadirse una explicación lexicográfica que permita comentar cómo el significado inherente a este adverbio puede ser explotado para desarrollar algunas estrategias argumentativas y para cumplir determinadas funciones pragmáticas. Veamos, a continuación, un modelo de explicación funcional de desgraciadamente que describe las intenciones comunicativas con las que puede ser empleado.

De una parte, al ser un adverbio cuyo significado puede implicar dolor o tristeza, desgraciadamente puede utilizarse para manifestar empatía al interlocutor en el momento de comunicarle una noticia trágica. Veamos un ejemplo de esta estrategia:

(7) Como ya le ha dicho mi compañero, su hijo ha ingresado en una situación gravísima, con el corazón parado... hemos estado más de una hora administrándole choques eléctricos y masaje cardíaco, pero desgraciadamente no ha sido posible recuperarlo... (CREA: Luis Jiménez de Diego, Memorias de un médico de Urgencias, 2002)

Esta elección de desgraciadamente sirve al médico para mostrarse afligido por el fallecimiento del paciente y, al mismo tiempo, para acompañar al familiar en su dolor y sufrimiento. Ahora bien, la introducción del adverbio no solamente responde a esta intención comunicativa, sino que obedece a otra estrategia que debe ser explicada. Al tratarse de un adverbio vinculado semánticamente a la 'fortuna adversa', el doctor lo utiliza también para intentar salvaguardar la imagen (cfr. el concepto en Brown y Levinson 1987) de su equipo médico y exculparlo de cualquier responsabilidad en el trágico final del paciente. Así, el deceso se presenta como consecuencia de la extrema gravedad del caso (su hijo ha ingresado en una situación gravísima, con el corazón parado) y como inevitable a pesar de los esfuerzos realizados (hemos estado más de una hora administrándole choques eléctricos y masaje cardíaco).

Para confirmar estas funciones pragmáticas del adverbio puede incluirse también en el diccionario el ejemplo siguiente, donde el autor del discurso se sirve del significado de desgraciadamente para apenarse por la muerte de unos polluelos y dejar entrever que la misma se ha debido a factores externos (la 'fortuna adversa') que escapan de su control y, por lo tanto, no a una imprudencia profesional:

(8) Así pues, cogimos a los cigoñinos -que, por cierto, no estaban nada lucidos-. Desgraciadamente, no fuimos capaces de sacarlos adelante. (CREA: José Ignacio Pardo de Santayana, El beso del chimpancé. Divertidas e insólitas historias de la vida cotidiana en un zoo, 2001)

Veamos ahora como la comparación de desgraciadamente con los otros adverbios acotados puede hacer referencia a los fines discursivos con los que el significado de estos signos puede ser explotado.

De una parte, el vínculo de infortunadamente con la 'mala suerte' facilita, al igual que el de desgraciadamente, su uso para minimizar la parte de culpabilidad con respecto a un desenlace negativo. Obsérvese, al respecto, el texto (9): 
(9) En cuanto a las chicas colombianas, infortunadamente se perdió el título suramericano que en Chile habían conseguido Cristina Baena, Catalina Zuluaga y Natalia Navarro. (CREA: El Tiempo, 28/04/1997)

En este ejemplo, el recurso a infortunadamente busca excusar al equipo colombiano por el decepcionante resultado obtenido, al dar a entender que la 'suerte adversa' ha sido un factor decisivo en la derrota. La protección de una imagen pública para evitar posibles críticas tras un desenlace desfavorable asemeja los usos de desgraciadamente y de infortunadamente, si bien este último, por su menor carga expresiva, no suele usarse tan frecuentemente en contextos trágicos.

Para cerrar estas explicaciones, puede apuntarse que desafortunadamente también comparte empleos para exponer una información negativa que defrauda las expectativas del interlocutor, como ilustra el siguiente diálogo:

(10) -Mi sistema antivirus identifica unos correos infectados por el virus W32.Klez.H. Los pongo en cuarentena y los elimino. Al ir luego a la bandeja de entrada de Outlook Express me los encuentro allí otra vez, intento eliminarlos, pero se abren automáticamente. ¿Qué puedo hacer? (Genoveva Dieterich)

-Desafortunadamente, tratándose del virus W32.Klez, no se puede estar seguro de que el sistema no esté infectado. (CREA: El País. Ciberpaís, 01/05/2003)

Aquí, la elección de desafortunadamente permite al autor de la segunda intervención introducir una respuesta que no va a satisfacer a Genoveva, quien había puesto sus esperanzas en el técnico para eliminar el virus. Ante la pregunta de esta última y consciente de que su respuesta no va a ser apreciada, el informático recurre al adverbio, cuyo vínculo con la ausencia de fortuna le ayuda a justificarse por no ofrecer una solución al problema. Además, la utilización del se impersonal en el discurso evaluado por desafortunadamente refuerza esta estrategia de conservación del prestigio profesional y de la imagen pública del locutor, que no asume su incapacidad para resolver el apuro del usuario.

Para terminar la comparación entre estos adverbios valorativos, conviene advertir que, como procedimiento de atenuación de la responsabilidad propia o ajena al exponer un resultado negativo, el recurso a desafortunadamente parece un mecanismo menos eficaz que el empleo de desgraciadamente o de infortunadamente, puesto que, a diferencia de estos dos últimos, el primero solo implica la falta de 'buena suerte'. Véase el siguiente texto, donde el uso de desafortunadamente intenta disculpar a un empresario del poco éxito profesional que ha tenido su representación teatral:

(11) Otro actor y empresario que busca a su "Don Juan" es Gonzalo Vega, quien desea presentar en la plaza de toros del restaurante de Chucho Arroyo la obra de "Don Juan Tenorio", en su versión clásica. Pero desafortunadamente se ha topado con la realidad. Los galanes de hoy temen al buen teatro. ¿Será porque están acostumbrados al apuntador de las telenovelas o a repetir múltiples veces sus escenas cuando graban alguna serie? (CREA: Excélsior, 14/09/2001) 
En este fragmento, aunque se intenta proteger la imagen y la reputación del empresario, la estrategia utilizada no parece la idónea para justificar el fracaso de la obra, ya que aludir a la mera 'ausencia de fortuna' que implica desafortunadamente y a encontrarse con una situación poco excepcional (se ha topado con la realidad) no parecen motivos suficientes para excusar al actor y empresario del decepcionante resultado conseguido.

\section{Conclusión}

En este trabajo hemos mostrado los problemas de utilización de diccionarios para aprender el funcionamiento concreto de algunas unidades evaluativas extrapredicativas del español y para conocer sus diferencias de empleo con respecto a otros signos del mismo paradigma. Para salvar estas deficiencias, hemos propuesto un modelo de análisis lexicográfico completo de estas palabras que da cuenta de sus valores sintácticos en la actualidad, que describe su significado en términos de instrucciones semántico-discursivas y que permite explicar, con ejemplos auténticos, cómo la información semántica de estos signos puede ser aprovechada para obtener efectos pragmáticos en el discurso.

Desde nuestro punto de vista, este tratamiento lexicográfico debería ser integrado progresivamente en diccionarios especializados en la descripción de partículas, cuya consulta y utilización es muy recomendable en el aprendizaje de una lengua, tanto por parte de hablantes nativos como por extranjeros ${ }^{18}$, para los cuales el uso de diccionarios bilingües tampoco garantiza la obtención de informaciones fiables ${ }^{19}$. El empleo de estos diccionarios especializados ofrece muchas aplicaciones para el aprendizaje de segundas lenguas o lenguas extranjeras, al ayudar al usuario no nativo de niveles avanzados a discriminar los usos entre unidades análogas y a utilizarlas correctamente en contextos reales.

\section{Referencias bibliográficas}

Alonso, J. I. (2000). Diccionario Espasa Grand: español-francés, français-espagnol. Madrid, Espasa Calpe.

\footnotetext{
${ }^{18}$ Las aplicaciones pedagógicas de estos repertorios lexicográficos son muy interesantes para el aprendizaje de lenguas por estudiante no nativos, a los que puede resultar difícil conocer las diferencias entre unidades afines de la lengua extranjera sin equivalencia directa en la lengua materna. Por ejemplo, nuestra experiencia docente e investigadora en Francia nos permite asegurar que para un francófono no es fácil distinguir desafortunadamente, infortunadamente y desgraciadamente, puesto que en francés solo malheureusement se ha especializado como adverbio disjunto de evaluación negativa. Sobre la comparación de los paradigmas de ambas lenguas, véase Meléndez Quero (2007). 19 Como muestra de las carencias de estos diccionarios bilingües, recordamos que el Diccionario Espasa Grand de Alonso (2000) no tiene entrada para desgraciadamente, desafortunadamente e infortunadamente, mientras que malheureusement solo es traducido mediante desgraciadamente. Por su parte, el diccionario Larousse (2009) no ofrece entrada para desafortunadamente o desgraciadamente, pero sorprendentemente sí para un adverbio en desuso como infortunadamente, traducido por malheureusement. Sin embargo, en la parte 'français-espagnol' del mismo diccionario, malheureusement equivale a desgraciadamente y por desgracia, sin que se haga referencia alguna a infortunadamente.
} 
Alvar Ezquerra, M. (dir.) (1993). Diccionario general ilustrado de la lengua española. Barcelona, Bibliograf. [VOX].

Azpiazu Torres, S. (1998-1999). ¿Es factible un diccionario de adverbios en -mente? Revista de lexicografía, 5, 7-32.

Battaner Arias, P. (2001). Lema: diccionario de la lengua española. Barcelona, Spes. [LEMA].

Briz, A., Pons Bordería, S. y J. Portolés (coords.) (2008): Diccionario de partículas discursivas del español. <http://www.dpde.es/>. [Consultado el 21.03.2015].

Brown, P. y S. C. Levinson (1987). Politeness. Some Universals in Language Use. Cambridge, Cambridge University Press.

Cazalaà, B. y P. Cabot (2009). Diccionario general español-francés, français-espagnol. Barcelona, Larousse. [Larousse].

Dik, S. (1989). The theory of functional grammar. Amsterdam, Dordrecht.

Donaire, M. L. (2006). Les dialogues intérieurs à la langue. Le Français Moderne, 74/1, 61-73.

Fernández Fernández, A. (1993). La función incidental en español. Hacia un nuevo modelo de esquema oracional. Oviedo, Universidad de Oviedo.

Fuentes Rodríguez, C. (2009). Diccionario de conectores y operadores del español. Madrid, Arco Libros.

Fuentes Rodríguez, C. y E. R. Alcaide Lara (1996). La expresión de la modalidad en el habla de Sevilla. Sevilla, Servicio de Publicaciones del Ayuntamiento de Sevilla.

González Ruiz, R. (2010). Los marcadores discursivos y su tratamiento lexicográfico. In Acín Villa, E. y O. Loureda Lamas (eds.), Los estudios sobre los marcadores del discurso, hoy, Madrid, Arco Libros, 617-688.

González Ruiz, R. y C. Llamas Saíz (eds.) (2011). Gramática y discurso. Nuevas aportaciones sobre partículas discursivas del español. Pamplona, Eunsa.

Greenbaum, S. (1969). Studies in English Adverbial Usage. Londres, Longman.

Hummel, M. (2012). Polifuncionalidad, polisemia y estrategias retóricas. Los signos discursivos con base atributiva entre oralidad y escritura. Acerca del uso de bueno, claro, total, realmente, etc. Berlín / Boston, De Gruyter.

Lara Ramos, L. F. (2003). El sentido de la definición lexicográfica. In Martín Zorraquino, M. A. y J. L. Aliaga Jiménez (eds.), La lexicografía hispánica ante el siglo XXI, Zaragoza, Institución Fernando el Católico, 99-113.

Loureda Lamas, O. y E. Acín Villa (eds.) (2010). Los estudios sobre los marcadores del discurso, hoy. Madrid, Arco Libros.

Martín Zorraquino, M. A. (1992). Partículas y modalidad. In Holtus, G. \& al. (eds.), Lexikon der Romanistichen Linguistik, Tubinga, Max Niemeyer Verlag, VI, 1, 110-124. (1999). Los marcadores del discurso en la enseñanza del español como lengua extranjera (Aspectos gramaticales y cuestiones pragmáticas). In Becerra Hiraldo, J. M. \& al. (eds.), La enseñanza de las segundas lenguas, Granada, Universidad de Granada, 51-79. 
------- (2003). Marcadores del discurso y diccionario: sobre el tratamiento lexicográfico de desde luego. In Echenique Elizondo, M. T. y J. Sánchez Méndez (eds.), Lexicografía y lexicología en Europa y América. Homenaje a Günther Haensch en su 80 aniversario, Madrid, Gredos, 439-453.

-------- (2006). Los marcadores del discurso en español: balance y perspectivas para su estudio. In Casado Velarde, M., R. González Ruiz y M. V. Romero Gualda (coords.), Análisis del discurso: lengua, cultura, valores, Madrid, Arco Libros, 43-64.

------- (2010a). Los marcadores del discurso y su morfología. In Esperanza Acín Villa, E. y O. Loureda Lamas (eds.), Los estudios sobre los marcadores del discurso, hoy, Madrid, Arco Libros, 92-180.

(2010b): «Las partículas discursivas en los diccionarios y los diccionarios de partículas discursivas (con referencia especial a desde luego / sin duda y por lo visto / al parecer. In Bernal, E. \& al. (eds.), Estudis de lexicografia 2003-2005, Barcelona, Universitat Pompeu Fabra, 231-257.

Martínez Marín, J. (2006). Los adverbios en -mente y los diccionarios modernos en español: perspectiva pragmático-discursiva. In Casado Velarde, M., R. González Ruiz y M. V. Romero Gualda (coords.), Análisis del discurso: lengua, cultura, valores, Madrid: Arco Libros, 1433-1444.

Meléndez Quero, C. (2007). Esp. afortunadamente, desgraciadamente / fr. heureusement, malheureusement: esbozo contrastivo de dos pares de partículas modales. Interlingüística, $17,737-747$.

------- (2009). Contribución al estudio de los adverbios disjuntos de valoración afectivoemotiva en español actual. Zaragoza, Universidad de Zaragoza. $<$ http://zaguan.unizar.es/record/2055>. [Consultado el 23.3.2015].

------- (2010). Comment expliquer la signification des particules discursives d'une langue étrangère? Les Cahiers de l'APLIUT, XXIX/1, 137-151.

(2011a). Los adverbios disjuntos de valoración emotiva en español actual. Vol.1. Saarbrücken, Editorial Académica Española.

------- (2011b). Los adverbios disjuntos de valoración emotiva en español actual. Vol.2. Saarbrücken, Editorial Académica Española.

(2011c). La construcción del discurso en la clase de Español Lengua Extranjera: los marcadores de acuerdo. In Guervós, J. de S. \& al. (eds.), Del texto a la lengua: la aplicación de los textos a la enseñanza-aprendizaje del español L2-LE, Salamanca, Kadmos, vol. 1, 605-620.

(2014). Retos y desafíos de la lexicografía para la enseñanza del español como lengua extranjera en el siglo XXI. In Contreras Izquierdo, N. M. (ed.), La enseñanza del español como LE / L2 en el siglo XXI, ASELE, Jaén, 473-484.

Moliner, M. (1966). Diccionario de uso del español. Madrid, Gredos, 2 vols. [DUE]. 
Perdiguero Villarreal, H. (2006). La definición de los adverbios de modo en los diccionarios de español. In Valencia, A. (ed.), XIV Congreso Internacional ALFAL, Santiago de Chile. [CD-Rom].

Porroche Ballesteros, M. (2005). Sobre francamente. In Castillo Carballo, M. A. \& al. (coords.), Las gramáticas y los diccionarios en la enseñanza del español como segunda lengua: deseo y realidad, Sevilla, Universidad de Sevilla, 693-699.

Porto Dapena, J. A. (2002). Manual de técnica lexicográfica. Madrid, Arco Libros.

Real Academia Española (2001). Diccionario de la lengua española. Madrid, Espasa Calpe, $22^{\mathrm{a}}$ edición. [DRAE].

(2015). Banco de datos (CREA). Corpus de Referencia del Español Actual. $<$ http://corpus.rae.es/creanet.html>. [Consultado el 18.3.2015].

Samper Padilla, J. A., C. E. Hernández Cabrera y M. Troya Déniz (eds.) (1997). Macrocorpus de la norma lingüística culta de las principales ciudades de España y América. Las Palmas de Gran Canaria, Universidad de Las Palmas de Gran Canaria. [CDRom].

Santos Río, L. (2003). Diccionario de partículas. Salamanca, Luso Española de Ediciones. Seco, M., O. Andrés y G. Ramos (1999). Diccionario del español actual. Madrid, Aguilar, 2 vols. [DEA].

Torner Castells, S. (2007). De los adjetivos calificativos a los adverbios en -mente: semántica y gramática. Madrid, Visor.

(2010). La definición de los adverbios en el diccionario monolingüe. In Bernal, E. \& al. (eds.), Estudis de lexicografia 2003-2005, Barcelona, Universitat Pompeu Fabra, 93108.

(2013). Suffix -mente adverbs in DAELE, a Spanish Learners' dictionary. International Journal of Lexicography, 26-4, 469-497.

Carlos Meléndez Quero

UMR 7118ATILF. 44 avenue de la Libération. BP 30687 - 54063 Nancy Cedex

0631767526

carlos.melendez@univ-lorraine.fr 